\title{
Gastrointestinal protozoa in non-human primates of four zoological gardens in Belgium
}

\author{
Bruno Levecke ${ }^{\mathrm{a}, *}$, Pierre Dorny ${ }^{\mathrm{a}, \mathrm{b}}$, Thomas Geurden ${ }^{\mathrm{a}}$, \\ Francis Vercammen ${ }^{\mathrm{c}}$, Jozef Vercruysse ${ }^{\mathrm{a}}$

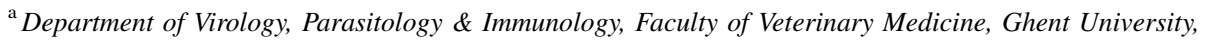 \\ Salisburylaan 133, 9820 Merelbeke, Belgium \\ ${ }^{\mathrm{b}}$ Department of Animal Health, Institute of Tropical Medicine, Nationalestraat 155, 2000 Antwerp, Belgium \\ ${ }^{\mathrm{c}}$ Veterinary Department, Royal Zoological Society of Antwerp, Koningin Astridplein 26, 2018 Antwerp, Belgium
}

Received 10 May 2007; received in revised form 10 June 2007; accepted 14 June 2007

\begin{abstract}
Gastrointestinal parasites are important infectious causes of diarrhoea in captive non-human primates (NHP). However, prevalence data of gastrointestinal parasites in zoological gardens are scarce. Therefore, a cross-sectional survey was conducted to estimate the occurrence of gastrointestinal parasites in NHP of four zoological gardens in Belgium. Between August 2004 and April 2006, 910 faecal samples were collected from 222 animals housed in 39 groups. The 31 species involved were representatives of prosimians, New World (NW) monkeys, Old World (OW) monkeys and apes. Because individual sampling was impossible, a statistical simulation was performed to estimate a sufficient sample size. All samples were microscopically examined after an acetic acid-ether concentration. Differences in host species susceptibility were examined by non-parametric tests. Entamoeba spp. (44\%) and Giardia spp. (41\%) were the most prevalent species. Other parasites detected were Endolimax nana (36\%), Chilomastix mesnili (21\%), Balantidium coli (13\%), Trichuris spp. (10\%), Iodamoeba bütschlii (5\%) and Strongyloides spp. (5\%). Parasites for which a significant difference in susceptibility at the level of host taxonomy was noted were Entamoeba spp. $(p<0.001)$ and $C$. mesnili $(p<0.05)$. Samples containing Entamoeba spp. were the most prevalent in OW monkeys $(p<0.0083)$. Samples collected from OW monkeys contained the highest number of parasite species $(p<0.0083)$.
\end{abstract}

(C) 2007 Elsevier B.V. All rights reserved.

Keywords: Gastrointestinal protozoa; Non-human primates; Zoological gardens; Prevalence; Host species susceptibility

\section{Introduction}

Infections with gastrointestinal parasites are widespread among non-human primates (NHP). However, as a consequence of regular deworming and hygienic measures helminth infections are uncommon in captive NHP (Gómez et al., 1996; Verweij et al., 2003a). In contrast, protozoa such as Entamoeba histolytica (Pang

\footnotetext{
* Corresponding author. Tel.: +329264 7404; fax: +329264 7496

E-mail address: bruno.levecke@ugent.be (B. Levecke).
}

et al., 1993; Verweij et al., 2003a), Giardia spp. (Peisert et al., 1983; Hamlen and Lawrence, 1994; Kalishman et al., 1996), Cryptosporidium spp. (Gómez et al., 1992; Kalishman et al., 1996; da Silva et al., 2003) and Balantidium coli (Nakauchi, 1999) are frequently reported in captive NHP, and are considered as important causes of gastro-enteritis in NHP. Infection by these gastrointestinal parasites may cause watery diarrhoea, hemorrhagic dysentery, extra-intestinal pathologies, such as liver abscesses, and even death. E. histolytica, the causative organism of invasive intestinal and extra-intestinal amebiasis, is of major 
concern. Clinical outbreaks and deaths caused by this parasite are frequently reported (Loomis et al., 1983; Beaver et al., 1988; Marquez-Monter et al., 1991; Verweij et al., 2003a). Giardiasis and cryptosporidiosis are of less clinical importance, but are considered as a cause of diarrhoea or failure to thrive in young animals (Miller et al., 1990; Kalishman et al., 1996). B. coli is probably harmless in most of the NHP species. However, according to Lee et al. (1990) and Hänichen et al. (1995) care should be taken when great apes are involved.

Because of the importance of E. histolytica (Stauffer and Ravdin, 2003), Giardia spp. (Thompson, 2000) and Cryptosporidium spp. (O'Donoghue, 1995) in humans, the role of NHP as potential reservoirs for zoonotic transmission should not be underestimated. Transmission between animals and humans in association with clinical outbreaks in animal caretakers has been reported in various studies (Miller et al., 1990; Hamlen and Lawrence, 1994).

Although the above-mentioned studies have shown the clinical importance of protozoa for both NHP and animal caretakers, studies to quantify the prevalence and importance of these parasites in zoological gardens are scarce. Most studies describe clinical outbreaks and were based on a limited number of animal and/or parasite species (Teare and Loomis, 1982; Loomis et al., 1983; Lee et al., 1990). Moreover, the strategies used to collect faecal samples may thwart the prevalence results.

In this study, the prevalence of gastrointestinal protozoa in NHP of four Belgian zoological gardens was estimated based on a new sampling strategy. In order to examine all animals within a group a statistical simulation was performed to estimate a sufficient sample size. The 31 species involved were representatives of NHP of four Belgian zoological gardens and included members of Lemuridae, Galagonidae, Cebidae, Atelidae, Cercopithecidae, Hylobatidae and Hominidae. A second objective was to examine differences in host species susceptibility to gastrointestinal protozoan infections.

\section{Materials and methods}

\subsection{Study sites}

This study was conducted at four Belgian zoological gardens. These included the Antwerp Zoo, the Animal Park Planckendael, the Olmen Zoo and the Park Paradisio. Because of confidentiality, a letter was randomly assigned to the four study sites. Study site A was founded in 1843 and is a typical urban zoo of about 10 ha where most of the NHP are accommodated in indoor enclosures. At study site B (12 ha), study site C (55 ha) and study site D (40 ha) the animals are kept on a large verdant outdoor enclosure. At all sites animals are kept indoor when the temperature drops below $10{ }^{\circ} \mathrm{C}$.

\subsection{Animals and husbandry}

From August 2004 to April 2006, 222 animals belonging to 31 NHP species and seven families were studied (Table 1). The families involved were two of prosimians (Lemuridae, Galagonidae), two of New World (NW) monkeys (Cebidae and Atelidae), one of the Old World (OW) monkeys (Cercopithecidae) and both families of the apes (Hylobatidae and Hominidae) (Groves, 2001). The animals are housed in 39 groups of 2-20 individuals (median of four animals). Apart from six groups where two NHP species are mixed, all groups consisted of one species. Of all sites, study site A lodges the largest and most diverse population of NHP. This site includes half of the animals and $75 \%$ of the species included in this study representing all seven families. A total of 37 animals (11 species) were examined at study site B, 38 animals (5 species) at study site C and 17 animals ( 3 species) at study site D.

Overall, the median (25th quantile (25Q); 75th quantile (75Q)) of the stocking density was $13.5 \mathrm{~m}^{2}$ per animal $(7.5 ; 51.1)$. The lowest values were found at study site A (median of $8.3 \mathrm{~m}^{2}$ per animal).

\subsection{Sampling strategy}

Due to the group housing of semi-wild NHP individual sampling was impossible. However, a statistical simulation in $\mathrm{R}$ (version 2.4.0, The $\mathrm{R}$ Foundation for Statistical Computing) was used to estimate the sample size needed to examine all animals within a group with a probability of at least $95 \%$ (Appendix A). Because little is known about the defecation behaviour of the different NHP species, an equal probability of sampling was assumed in this simulation $\left(\pi_{1}=\pi_{2}=\cdots=\pi_{j}=1 / n \_\mathrm{NHP}\right)$. To correct for this unknown variability, a sampling method with replacement was performed (group $\sim \operatorname{Mult}\left(n \_\operatorname{sim}, \pi\right)$ ). The estimated sample sizes in function of the group size obtained by this simulation are presented in Table 2.

For each particular group all samples were picked up from the ground during consecutive days until the estimated sample size was approximated. 
Table 1

Animal species and husbandry conditions of NHP kept at four Belgian zoological gardens

\begin{tabular}{|c|c|c|c|}
\hline \multicolumn{2}{|l|}{ Groups } & \multirow{2}{*}{$\begin{array}{l}\text { Number of } \\
\text { animals }\end{array}$} & \multirow{2}{*}{$\begin{array}{l}\text { Stocking density } \\
\left(\text { animal } / \mathrm{m}^{2}\right)\end{array}$} \\
\hline Common name & Scientific name & & \\
\hline \multicolumn{4}{|l|}{ Study site A } \\
\hline Ring-tailed lemur & Lemur catta & 9 & 12.0 \\
\hline Red ruffed lemur & Varecia rubra & 2 & 7.5 \\
\hline Red ruffed lemur & Varecia rubra & 4 & 3.5 \\
\hline Brown greater galago & Otolemur crassicaudatus & 2 & 60.0 \\
\hline Goeldi's marmoset & Callimico goeldii & 2 & $3.7^{\mathrm{a}}$ \\
\hline Golden-headed lion tamarin & Leontopithecus chrysomelas & 2 & \\
\hline Common marmoset & Callithrix jacchus & 1 & $3.3^{\mathrm{a}}$ \\
\hline Golden-headed lion tamarin & Leontopithecus chrysomelas & 2 & \\
\hline Common marmoset & Callithrix jacchus & 2 & $4.0^{\mathrm{a}}$ \\
\hline Golden-headed lion tamarin & Leontopithecus chrysomelas & 2 & \\
\hline Pygmy marmoset & Callithrix pygmae & 10 & 1.2 \\
\hline Emperor tamarin & Saguinus imperator & 2 & 7.5 \\
\hline Black-headed spider monkey & Ateles fusciceps & 5 & 13 \\
\hline Celebes crested macaque & Macaca nigra & 2 & 19.9 \\
\hline Mandrill & Mandrillus sphinx & 14 & 17.9 \\
\hline Hamadryas baboon & Papio hamadryas & 20 & 8.1 \\
\hline Mantled guereza & Colobus guereza & 7 & 4.3 \\
\hline Hamlyn’s monkey & Cercopithecus hamlyni & 8 & 8.5 \\
\hline Northern plains gray langur & Semnopithecus entellus & 5 & 7.9 \\
\hline Javan lutung & Trachypithecus auratus & 4 & 3.7 \\
\hline Javan lutung & Trachypithecus auratus & 6 & 11.4 \\
\hline Siamang & Hylobates syndactylus & 4 & 12.0 \\
\hline Western lowland gorilla & Gorilla gorilla & 1 & $78.7^{\mathrm{a}}$ \\
\hline Mountain gorilla & Gorilla beringei & 2 & \\
\hline Common chimpanzee & Pan troglodytes & 10 & 15.7 \\
\hline Bornean Orangutan & Pongo pygmaeus & 2 & 83.0 \\
\hline \multicolumn{4}{|l|}{ Study site B } \\
\hline Black-and-white ruffed lemur & Varecia variegata & 6 & $31.0^{\mathrm{a}}$ \\
\hline Ring-tailed lemur & Lemur catta & 3 & $19.5^{\mathrm{a}}$ \\
\hline Brown lemur & Eulemur fulvus & 1 & \\
\hline Tufted capuchin & Cebus apella & 5 & 44.4 \\
\hline Common squirrel monkey & Saimiri sciureus & 6 & 2.5 \\
\hline Common marmoset & Callithrix jacchus & 2 & 1.0 \\
\hline Black crested mangabey & Lophocebus aterrimus & 5 & 9.3 \\
\hline Black crested gibbon & Hylobates concolor & 1 & $14.0^{\mathrm{a}}$ \\
\hline Red-cheeked gibbon & Hylobates gabriellae & 1 & \\
\hline White-handed gibbon & Hylobates lar & 4 & 44.5 \\
\hline Common chimpanzee & Pan troglodytes & 3 & 161.7 \\
\hline \multicolumn{4}{|l|}{ Study site C } \\
\hline Ring-tailed lemur & Lemur catta & 8 & 253.0 \\
\hline Red ruffed lemur & Varecia rubra & 4 & 257.4 \\
\hline Black-and-white ruffed lemur & Varecia variegata & 4 & 127.2 \\
\hline Common squirrel monkey & Saimiri sciureus & 20 & 51.1 \\
\hline Siamang & Hylobates syndactylus & 2 & NA \\
\hline \multicolumn{4}{|l|}{ Study site D } \\
\hline White-handed gibbon & Hylobates lar & 4 & 132.2 \\
\hline Northern white-cheeked gibbon & Hylobates leucogenys & 4 & 32.3 \\
\hline Bonobo & Pan paniscus & 9 & 347.9 \\
\hline
\end{tabular}

NA: not available.

${ }^{\mathrm{a}}$ Both NHP species are housed in the same enclosures. 
Table 2

Estimated sample sizes and probabilities in relation to different group sizes

\begin{tabular}{lcl}
\hline Group size & Samples size & $\begin{array}{l}\text { Probability }(\%) \\
(95 \% \text { confidence interval) }\end{array}$ \\
\hline 2 & 6 & $96.8(96.5 ; 97.2)$ \\
3 & 11 & $96.6(96.2 ; 96.9)$ \\
4 & 16 & $96.4(96.0 ; 96.8)$ \\
5 & 21 & $95.6(95.1 ; 96.0)$ \\
6 & 27 & $95.6(95.2 ; 96.0)$ \\
7 & 33 & $95.8(95.4 ; 96.2)$ \\
8 & 38 & $95.3(95.0 ; 95.8)$ \\
9 & 45 & $95.4(95.0 ; 95.8)$ \\
10 & 50 & $95.2(95.0 ; 95.6)$ \\
11 & 58 & $95.5(95.1 ; 95.9)$ \\
14 & 76 & $95.4(95.0 ; 95.8)$ \\
20 & 116 & $95.4(95.0 ; 95.8)$ \\
\hline
\end{tabular}

\subsection{Coprological examination}

An acetic acid-ether concentration method on faeces was used to demonstrate the presence of gastrointestinal parasites in NHP (Thienpont et al., 1986). Half a gram of faeces was suspended in $5 \mathrm{ml}$ acetic acid (5\%) and strained through a brush wire sieve to remove debris. The fat in the resulting filtrate was removed by emulsifying the sample with $5 \mathrm{ml}$ of ether followed by centrifugation at $1500 \mathrm{rpm}$ for $2 \mathrm{~min}$. The resulting supernatant (ether, debris and acetic acid) was discarded and two drops of diluted iodine (1:100) were added to the remaining sediment. The stained sediment was thoroughly mixed after which it was transferred onto a glass microscope slide and covered with a cover glass. Each sample was examined at a $400 \times$ magnification for the presence of eggs, larvae, trophozoites and/or cysts.

\subsection{Statistical analysis}

'Prevalence' is defined as the percentage of groups of NHP infected with a particular parasite species and 'diversity' as the number of parasite species within the same group. 'Proportion' describes the proportion of samples containing a particular parasite species within the same group and 'multiple infections' the median number of parasite species found in these samples. Entamoeba spp. was treated as one species. The Kruskal-Wallis test was performed to test for differences in proportion and mixed infections between host species (SAS 9.1.3, SAS Institute Inc., Cary, NC, USA). The host species' classes involved were prosimians, NW monkeys, OW monkeys and apes. The level of significance was set at $P<0.05$. In addition, a Bonferroni pair wise comparison procedure was performed. For this, the Wilcoxon test was employed and the level of significance was set at 0.0083 (SAS 9.1.3, SAS Institute Inc., Cary, NC, USA).

\section{Results}

In total, 910 individual samples were collected. The number of times a group was sampled varied between 1

Table 3

Prevalence and diversity of parasites in NHP at four Belgian zoological gardens

\begin{tabular}{|c|c|c|c|c|c|c|c|c|c|c|}
\hline & $\begin{array}{l}\text { Number of } \\
\text { groups }\end{array}$ & $\begin{array}{l}\text { Entamoeba } \\
\text { spp. }(\%)\end{array}$ & $\begin{array}{l}\text { E. nana } \\
(\%)\end{array}$ & $\begin{array}{l}\text { I. bütschlii } \\
(\%)\end{array}$ & $\begin{array}{l}\text { Giardia } \\
\text { spp. (\%) }\end{array}$ & $\begin{array}{l}\text { C.mesnili } \\
(\%)\end{array}$ & $\begin{array}{l}\text { B. coli } \\
(\%)\end{array}$ & $\begin{array}{l}\text { Trichuris } \\
\text { spp. (\%) }\end{array}$ & $\begin{array}{l}\text { Strongyloides } \\
\text { spp. }(\%)\end{array}$ & $\begin{array}{l}\text { Diversity } \\
(25 Q-75 Q)\end{array}$ \\
\hline Prosimians & 9 & 33 & 11 & 0 & 44 & 11 & 0 & 0 & 0 & $0-2$ \\
\hline Study site A & 4 & 50 & 0 & 0 & 25 & 25 & 0 & 0 & 0 & \\
\hline Study site B & 2 & 50 & 50 & 0 & 100 & 0 & 0 & 0 & 0 & \\
\hline Study site C & 3 & 0 & 0 & 0 & 33 & 0 & 0 & 0 & 0 & \\
\hline NW monkeys & 10 & 40 & 40 & 0 & 40 & 0 & 0 & 0 & 0 & $0-2$ \\
\hline Study site A & 6 & 17 & 17 & 0 & 33 & 0 & 0 & 0 & 0 & \\
\hline Study site B & 3 & 67 & 67 & 0 & 33 & 0 & 0 & 0 & 0 & \\
\hline Study site C & 1 & 100 & 100 & 0 & 100 & 0 & 0 & 0 & 0 & \\
\hline OW monkeys & 9 & 100 & 44 & 22 & 22 & 55 & 33 & 33 & 0 & $1-5$ \\
\hline Study site A & 8 & 100 & 50 & 12 & 25 & 50 & 37 & 37 & 0 & \\
\hline Study site B & 1 & 100 & 0 & 100 & 0 & 100 & 0 & 0 & 0 & \\
\hline Apes & 11 & 64 & 45 & 0 & 54 & 18 & 18 & 1 & 18 & $1-3$ \\
\hline Study site A & 4 & 100 & 25 & 0 & 75 & 25 & 25 & 0 & 25 & \\
\hline Study site B & 3 & 67 & 0 & 0 & 33 & 33 & 0 & 33 & 0 & \\
\hline Study site C & 1 & 100 & 100 & 0 & 100 & 0 & 0 & 0 & 0 & \\
\hline \multirow[t]{2}{*}{ Study site D } & 3 & 0 & 100 & 0 & 33 & 0 & 33 & 0 & 33 & \\
\hline & 39 & 59 & 36 & 5 & 41 & 21 & 13 & 10 & 5 & $1-3$ \\
\hline
\end{tabular}


and 11 occasions and the median number of faecal samples produced by the groups measured 1 per animal, ranging from 0.15 to 8 . The median $(25 \mathrm{Q} ; 75 \mathrm{Q})$ probability of sampling all animals within a group was 96\% (93-97).

\subsection{Prevalence and diversity of parasites}

A total of eight parasite species were identified, two protozoan and two nematode species. Prevalence and diversity of gastrointestinal parasites are reported in Table 3. Infections with trematodes and cestodes were not detected. In 33 out of the 39 groups, infection with at least one parasite species was detected. The most prevalent gastrointestinal parasites were: Entamoeba spp. (59\%), and Giardia spp. (41\%). Other parasites detected were Endolimax nana (36\%), Chilomastix mesnili (21\%), B. coli (13\%), Trichuris spp. (10\%), Iodamoeba bütschlii (5\%) and Strongyloides spp. (5\%). All parasite species were detected in no less than two study sites. Giardia spp. and $E$. nana were the only parasite species observed at all the four study sites. Groups of OW monkeys harboured the most parasite species. In these groups the median number of parasite species detected was three. The smallest diversity was observed in NW monkeys and prosimians (median of one parasite species).

\subsection{Proportion and multiple infections}

Tables 4-7 provide an overview of the results. Overall, there was a large variation in proportion of parasite infections. For the most prevalent parasite species, the proportion ranged from 0 to $100 \%$ for Entamoeba spp., and from 0 to $94 \%$ for Giardia spp. For Entamoeba spp., the highest proportion was found in OW monkeys. The median (25Q; 75Q) of proportion in these host species measured $87.5 \%(80.0 ; 96.0)$. In Apes, Entamoeba spp. occurred in $12.5 \%(0 ; 62.5)$ of the samples. Prosimians and NW monkeys were the least infected with this parasite species. Entamoeba spp. was not detected in $75 \%$ of these host species. Samples containing cysts of Giardia spp. were mainly found in apes. The median proportion in these NHP species was $4 \%(0 ; 38.8)$. The least proportion of this infection was observed in OW monkeys, in which no cysts were found in $75 \%$ of the groups. The less common parasites were mainly found in OW monkeys. Overall, the median of the multiple infections measured 1, ranging from 0 to 3 . OW monkeys harboured the most species of endoparasites. In these groups the median $(25 \mathrm{Q} ; 75 \mathrm{Q})$ number of infections detected was $1(1 ; 2), 1$ in apes $(0 ; 1)$ and 0 in both NW monkeys $(0 ; 1)$ and prosimians $(0 ; 0)$.

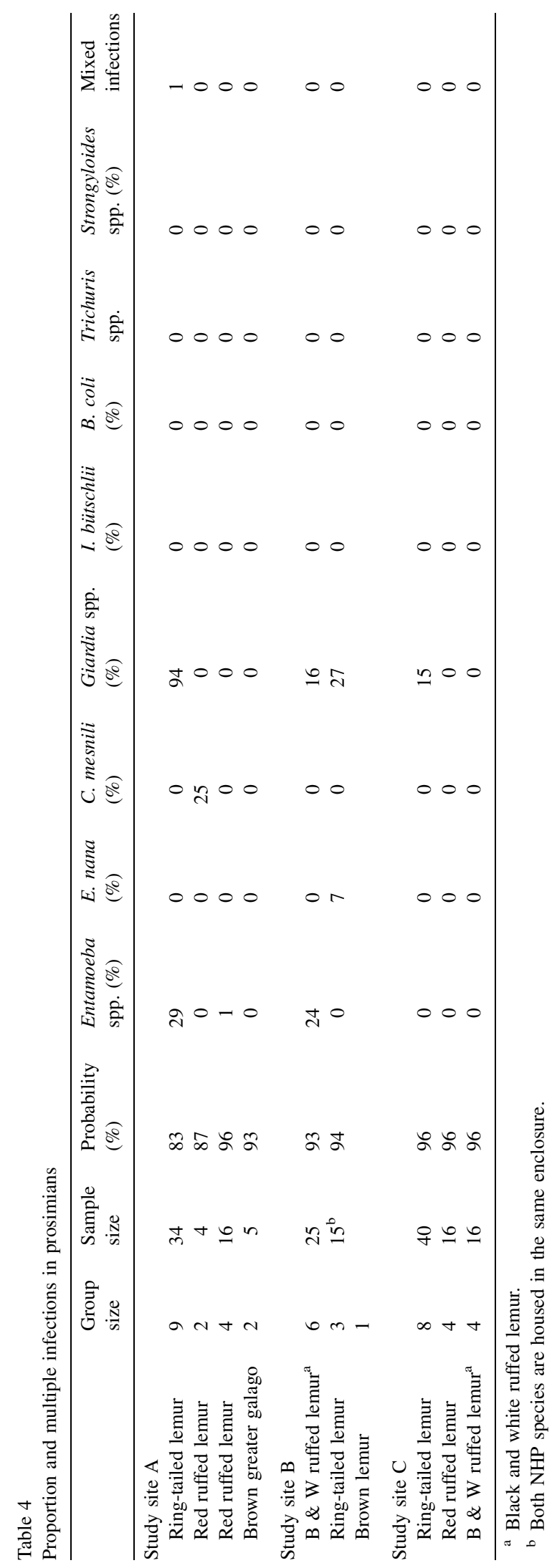


Table 5

Proportion and multiple infections in NW monkeys

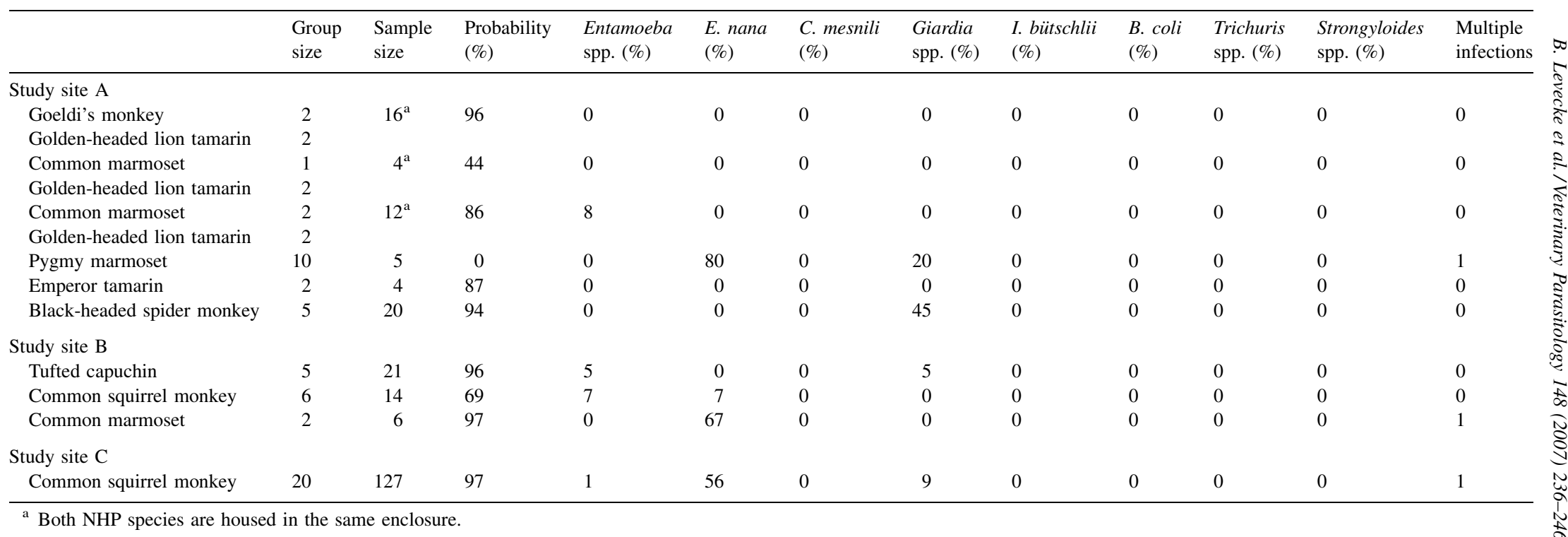




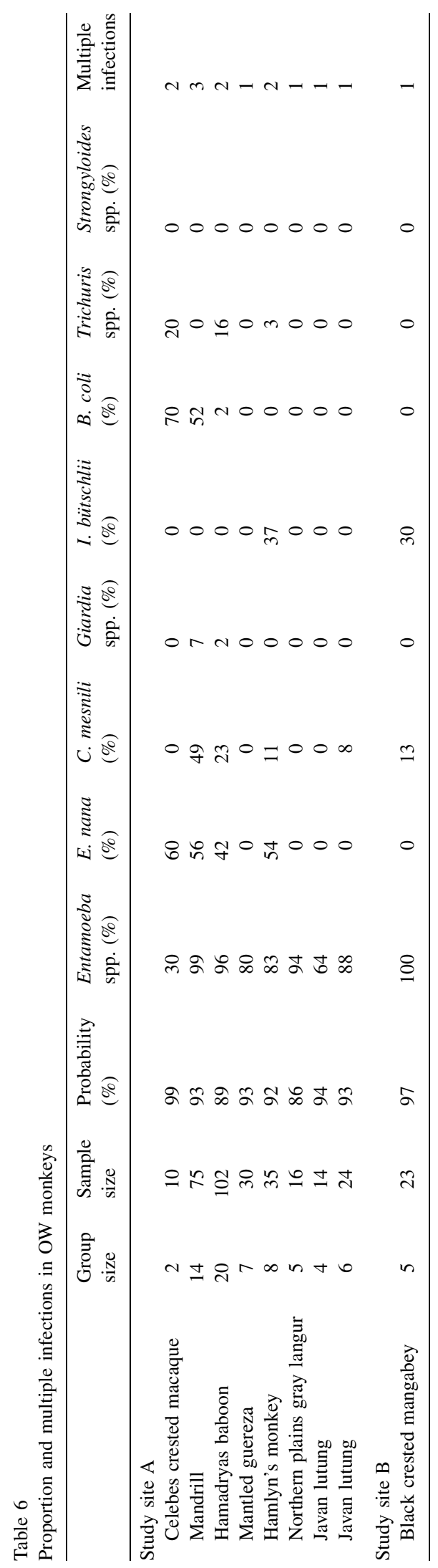

No significant effects were found of study sites on proportion of infections $\left(\chi^{2}(3)=0.80-6.0, p=0.84\right.$ $0.11)$ and multiple infections $\left(\chi^{2}(3)=4.2, p>0.2\right)$, neither for stocking density $(R=-0.17$ to 0.001 , $\left.p=0.32-0.99 ; \chi^{2}(3)=0.77, p>0.8\right)$.

\subsection{Differences in host species susceptibility}

Both proportion and multiple infections $\left(\chi^{2}(3)=19.9\right.$, $p=0.0002)$ differed between host species. Parasites for which a significant difference in susceptibility at the level of taxonomy was noted were Entamoeba spp. $\left(\chi^{2}(3)=21.4, p<0.0001\right)$ and C. mesnili $\left(\chi^{2}(3)=9.3\right.$, $p<0.05)$. However, a marginal $p$-value was also found for I. bütschlii $\left(\chi^{2}(3)=6.8, p=0.08\right)$, Trichuris spp. $\left(\chi^{2}(3)=6.8, p=0.08\right)$ and B. $\operatorname{coli}\left(\chi^{2}(3)=6.4, p=0.09\right)$. Samples containing cysts of Entamoeba spp. were more prevalent in OW monkeys than in prosimians $(|Z|=3.6$, $p<0.0005)$, in NW monkeys $(|Z|=3.7, p<0.0005)$ and in apes $(|Z|=2.7, p<0.0083)$. OW monkeys had a marginal significantly higher number of infected samples with $C$. mesnili than NW monkeys $(|Z|=2.6$, $p=0.0099)$. Samples collected from OW monkeys contained the highest number of parasite species (prosimians: $|Z|=3.5, \quad p<0.0005$; NW monkeys: $|Z|=3.2, p<0.005$; apes: $|Z|=2.8, p<0.0083)$. No significant differences were observed between the other host species.

\section{Discussion}

In the present study, the majority of the examined groups were infected with at least one parasite species. All the parasite species identified in our study have previously been described in both captive and free ranging NHP (Gómez et al., 1996; Ashford and Wrangham, 2000; Legesse and Erko, 2004). Protozoa were most prevalent, which confirms the findings of other studies performed in captive NHP (Gómez et al., 1996; Verweij et al., 2003a). The occurrence of these parasites can be explained by the simplicity of their lifecycle, because they need no intermediate hosts and are immediately infective when excreted. Moreover, the low infective dose and the short prepatent period, obviously ease transmission (Tanyuksel and Petri, 2003; Thompson and Monis, 2004). The most prevalent parasite species in this study were Entamoeba spp. and Giardia spp. More than $40 \%$ of the examined groups were infected with one of these endoparasites. However, a large variation in proportion and multiple infections was observed between the examined groups. This variation may be caused by differences in host species 
Table 7

Proportion and multiple infections in apes

\begin{tabular}{|c|c|c|c|c|c|c|c|c|c|c|c|c|}
\hline & $\begin{array}{l}\text { Group } \\
\text { size }\end{array}$ & $\begin{array}{l}\text { Sample } \\
\text { size }\end{array}$ & $\begin{array}{l}\text { Probability } \\
(\%)\end{array}$ & $\begin{array}{l}\text { Entamoeba } \\
\text { spp. }(\%)\end{array}$ & $\begin{array}{l}\text { E. nana } \\
(\%)\end{array}$ & $\begin{array}{l}\text { C. Mesnili } \\
(\%)\end{array}$ & $\begin{array}{l}\text { Giardia } \\
\text { spp. }(\%)\end{array}$ & $\begin{array}{l}\text { I. bütschlii } \\
(\%)\end{array}$ & $\begin{array}{l}\text { B. coli } \\
(\%)\end{array}$ & $\begin{array}{l}\text { Trichuris } \\
\text { spp. }(\%)\end{array}$ & $\begin{array}{l}\text { Strongyloides } \\
\text { spp. }(\%)\end{array}$ & $\begin{array}{l}\text { Multiple } \\
\text { infections }\end{array}$ \\
\hline \multicolumn{13}{|l|}{ Study site A } \\
\hline Siamang & 4 & $15^{\mathrm{b}}$ & 94 & 27 & 0 & 0 & 47 & 0 & 0 & 0 & 7 & 1 \\
\hline Western lowland gorilla ${ }^{\mathrm{a}}$ & 1 & $3^{\mathrm{b}}$ & 100 & 67 & 0 & 0 & 67 & 0 & 0 & 0 & 0 & 1 \\
\hline Mountain gorilla $^{a}$ & 2 & & & & & & & & & & & \\
\hline Common chimpanzee & 10 & 49 & 94 & 8 & 8 & 2 & 39 & 0 & 29 & 0 & 0 & 1 \\
\hline Bornean orang-utan ${ }^{\mathrm{a}}$ & 2 & 8 & 100 & 62 & 0 & 0 & 0 & 0 & 0 & 0 & 0 & 1 \\
\hline \multicolumn{13}{|l|}{ Study site B } \\
\hline White-handed gibbon & 4 & 16 & 96 & 12 & 0 & 0 & 12 & 0 & 0 & 0 & 0 & 0 \\
\hline Black crested gibbon $^{\mathrm{a}}$ & 1 & $3^{\mathrm{b}}$ & 100 & 0 & 0 & 0 & 0 & 0 & 0 & 33 & 0 & 0 \\
\hline Red-cheeked gibbon ${ }^{\mathrm{a}}$ & & & & & & & & & & & & \\
\hline Common chimpanzee & 3 & 11 & 97 & 100 & 0 & 45 & 0 & 0 & 0 & 0 & 0 & 1 \\
\hline \multicolumn{13}{|l|}{ Study site C } \\
\hline Siamang & 2 & 10 & 99 & 60 & 10 & 0 & 20 & 0 & 0 & 0 & 0 & 1 \\
\hline \multicolumn{13}{|l|}{ Study site D } \\
\hline White-handed gibbon & 4 & 18 & 97 & 0 & 6 & 0 & 0 & 0 & 0 & 0 & 0 & 0 \\
\hline Northern w-c gibbon ${ }^{c}$ & 4 & 26 & 99 & 0 & 12 & 0 & 4 & 0 & 11 & 0 & 42 & 1 \\
\hline Bonobo $^{\mathrm{a}}$ & 9 & 22 & 100 & 0 & 41 & 0 & 0 & 0 & 0 & 0 & 0 & 0 \\
\hline
\end{tabular}

${ }^{\mathrm{a}}$ Individual samples.

${ }^{\mathrm{b}}$ Both species are housed in the same enclosure.

${ }^{c}$ Northern white-cheeked gibbon. 
susceptibility, since OW monkeys were at higher risk of infections, including those with Entamoeba spp. and harboured the highest number of parasite species. Differences in host species susceptibility have been hypothesized and might be explained by differences in behaviour, because the majority of the OW monkeys are ground dwellers (Beaver et al., 1988; Munene et al., 1998).

Using the sample strategy described in this study, more insights were gained in the epidemiology of gastrointestinal parasites in NHP of zoological gardens. First of all, it is likely to result in more accurate estimates of the group's prevalence, because all animals were examined with a high probability and none of the samples were pooled. Moreover, it allowed a more powerful risk factor analysis, since proportion within groups could be estimated.

Of all parasites identified in this study, Giardia spp., $B$. coli, Trichuris spp. and Strongyloides spp. might cause gastrointestinal enteritis in NHP (Lee et al., 1990; Hamlen and Lawrence, 1994; Hänichen et al., 1995; Kalishman et al., 1996). However, due to the study design the clinical importance of these infections could not be studied more in depth, in particular for E. histolytica. E. histolytica has been previously described in various species involved in this study (Loomis et al., 1983; Beaver et al., 1988; Verweij et al., 2003a; Mätz-Rensing et al., 2004), but differentiation between other Entamoeba spp. (E. coli, E. hartmanii, E. polecki-like) is difficult (Verweij et al., 2001, Kebede et al., 2003) and even impossible when E. dispar or E. moshkovskii are involved (Diamond and Clark, 1993, Tanyuksel and Petri, 2003). For this purpose molecular diagnostic techniques are more appropriate (Verweij et al., 2003b). Among other pathogenic parasites that cannot be ruled out in the present study was Cryprosporidium spp. (Miller et al., 1990; Muriuki et al., 1997; Gómez et al., 2000), because no appropriate detection technique was used.

Although all parasites found are recognised zoonotic pathogens, the high prevalence of Giardia warrants special attention. Zoonotic assemblages (G. duodenalis assemblage A and B) have been described in NHP (Thompson et al., 2000; Graczyk et al., 2002; Nizeyi et al., 2002, Vitazkova and Wade, 2006). However, differentiation of the assemblages of $G$. duodenalis based morphological features is impossible, and therefore additional prevalence data based on molecular techniques are needed to confirm this reservoir function of NHP involved in this study. In conclusion, the results of this study demonstrated that gastrointestinal protozoa and multiple infections are highly prevalent in NHP of Belgian zoos. There was a large variation in proportion and multiple infections between groups of NHP, which might be explained by differences in host species susceptibility. The used sample strategy is likely to result in more accurate epidemiological data. This study also emphasizes the need for molecular diagnostic tools in NHP to evaluate the clinical importance and zoonotic risk of these infections.

\section{Acknowledgements}

This work received financial support from the Centre of Research and Conservation of The Royal Zoological Society of Antwerp, which is supported by the Flemish Government (Dehousse grant). 


\section{Appendix A}

n_NHP $<$-number of an imals within a group;

min_n_samples $<-$ minimum number of samples;

max_n_sa mples $<-$ maximum number of samples;

n_sim <- number of iterations needed to obtain estimates. This was set on 10000;

miss $<-$ rep(0,max_n_samples $)$

$\operatorname{miss}[\mathrm{i}]=$ the number of times at least one animal within a group was not sampled when $\mathrm{i}$

faecal samples were collected. This vector contains 0's on the onset of the simulation.

for (i in min_n_samples:max_n_samples)

\{

For each sample size i varying between min_n_samples and max_n_samples a simulation will be performed.

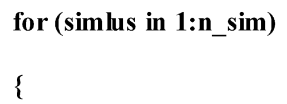

Each simulation consists of 10000 iterations

$$
\text { group <- rep(0,n_NHP); }
$$

group[j] equals the number of faecal samples collected of animal $j$ within a group. This vector contains only 0 's on the onset of the sampling.

\section{for (lus in 1:i)}

\{

$$
\begin{aligned}
& \text { j <-sample(1:n_NHP,1); } \\
& \operatorname{group}(\mathbf{j})=\operatorname{group}(\mathrm{j})+1 ;
\end{aligned}
$$

group $\sim \operatorname{Mult}\left(\mathrm{n} \_\operatorname{sim}, \pi\right)$, where $\pi=\left(\pi_{1} \pi_{2} \ldots \pi_{\mathrm{j}}\right)$ and $\pi_{1}=\pi_{2}=\ldots=\pi_{\mathrm{j}}=1 / \mathrm{n} \_$NHP

\}

ifeke $($ any $($ group $==0$, na.rm $=$ TRUE $)==$ TRUE, miss $[\mathbf{i}]<-$ miss $[\mathbf{i}]+1$, $\operatorname{miss}[\mathrm{i}]<-\operatorname{miss}[\mathrm{i}]+\mathbf{0})$

\}

The sample size i will increase with one unit

\}

$\operatorname{prob}=$ miss/n_sim;

prob[i] equals the probability of missing at least one animal in a group of $n_{-}$NHP animals when i faecal samples were collected.

$\operatorname{prob}[\mathrm{i}] \sim \operatorname{binom}\left(\mathrm{n} \_\operatorname{sim}, \operatorname{prob}[\mathrm{i}]\right)$ 


\section{References}

Ashford, R.W., Wrangham, R.W., 2000. Intestinal parasites of the chimpanzee Pan troglodytes in Kibale Forest, Uganda. Ann. Trop. Med. Parasitol. 94, 173-179.

Beaver, P.C., Blanchard, J.L., Seibold, H.R., 1988. Invasive amebiasis in naturally infected New World and Old World monkeys with and without clinical disease. Am. J. Trop. Med. Hyg. 39, 343-352.

da Silva, A.J., Cacció, S., Williams, C., Won, K.Y., Nace, E.K., Whittier, C., Pieniazek, N.J, Behard, M.E., 2003. Molecular and morphologic characterization of a Cryptospordium genotype identified in lemurs. Vet. Parasitol. 111, 297-307.

Diamond, L.S., Clark, C.G., 1993. A rescription of Entamoeba histolytica Schaudinn, 1903 (Emended Walker, 1911) separating it from Entamoeba dispar Brumpt, 1925. J. Eukaryot. Microbiol. 40, 340-344.

Gómez, M.S., Gracenea, M., Gosalbez, P., Feliu, C., Enseñat, C., Hidalgo, R., 1992. Detection of oocysts of Cryptosporidium in several species of monkeys and in one prosimian species at the Barcelona Zoo. Parasitol. Res. 78, 619-620.

Gómez, M.S., Gracenea, M., Montoliu, I., Feliu, C., Monleon, A., Fernandez, J., Enseñat, C., 1996. Intestinal parasitism - protozoa and helminths - in primates at the Barcelona Zoo. J. Med. Primatol. 25, 419-423.

Gómez, M.S., Torres, J., Gracenea, M., Fernadez-Morán, J., GonzalesMoreno, O., 2000. Further report on Cryptosporidium in Barcelona zoo mammals. Parasitol. Res. 86, 318-323.

Graczyk, T.K., Bosco-Nizeyl, J., Ssebide, B., Thompson, R.C.A., Read, C., Cranfield, M.R., 2002. Anthropozoonotic Giardia duodenalis genotype (assemblage) A infections in habitats of freeranging human-habituated gorillas, Uganda. J. Parasitol. 88, 905-909.

Groves, C.P., 2001. In: D’Araujo, E. (Ed.), Primate Taxonomy. Smithsonian Institution Press, London, p. 350.

Hamlen, H.J., Lawrence, J.M., 1994. Giardiasis in laboratory-housed squirrel monkeys: a retrospective study. Lab. Anim. Sci. 44, 235-239.

Hänichen, T., Wiegand, F., von Hegel, G., 1995. Enterocolitis accompanied by protozoan and metazoan parasites in anthropoid apes. In: Verhandlungsbericht des 37 Internationalen Symposiums über Die Erkrankungen der Zoo und Wildtiere, 24-28 mei 1995, Dresden.

Kalishman, J., Paul-Murphy, J., Scheffer, J., Thomson, J.A., 1996. Survey of Cryptosporidium and Giardia spp. in a captive population of common marmosets. Lab. Anim. Sci. 46, 116-119.

Kebede, A., Verweij, J.J., Dorigo-Zetsma, J., Sanders, E., Messele, T., Vanlieshout, L., Petros, B., Polderman, A., 2003. Overdiagnosis of amoebiasis in the abscence of Entamoeba histolytica among patients presenting with diarrhoea in Wonji and Akaki, Ethiopia. Trans. Roy. Soc. Trop. Med. Hyg. 97, 305-307.

Lee, R.V., Prowten, A.W., Anthone, S., Satchidanand, S.K., Fisher, J.E., Anthone, R., 1990. Typhlitis due to Balantidium coli in captive lowland gorillas. Rev. Infect. Dis. 12, 1052-1059.

Legesse, M., Erko, B., 2004. Zoonotic intestinal parasites in Papio anubis (baboon) and Cercopithecus aethiops (vervet) from four localities in Ethiopia. Acta Trop. 90, 231-236.

Loomis, M.R., Britt, J.O., Gendron, A.P., Holshuh, H.J., Howard, E.B., 1983. Hepatic and gastric amebiasis in black and white colobus monkeys. J. Am. Vet. Med. Assoc. 183, 1188-1191.

Marquez-Monter, H., Fuentes-Orozco, R., Correa-Lemus, I., Becker, I., 1991. Invasive amebiasis in a spider monkey (Ateles geoffroyi).
Case report and a short review of the literature of amebiasis in nonhuman primates. Arch. Invest. Med. 22, 75-78.

Mätz-Rensing, K., Floto, A., Kaup, F.-J., Schaller, K., 2004. Gastric amebiasis due to Entamoeba histolytica infection in a mandrill (Mandrillus spinx). In: European Association of Zoo and Wildlife Veterinarians 5th Scientific Meeting, 2004, Ebeltoft, pp. 325-327.

Miller, R.A., Brondson, M.A., Kuller, L., Morton, W.R., 1990. Clinical and parasitologic aspects of cryptosporidiosis in nonhuman primates. Lab. Anim. Sci. 40, 42-46.

Munene, E., Otsyula, M., Mbaabu, D., Mutahi, W.T., Muriuki, S.M.K., 1998. Helminth and protozoan gastro-intestinal (GIT) parasites in captive and wild-trapped African non-human primates. Vet. Parasitol. 78, 1995-2201.

Muriuki, S.M.K., Farah, I.O., Kagwiria, R.M., Chai, D.C., Njamunge, G., Suleman, M., Olobo, J.O., 1997. The presence of Cryptosporidium oocysts in stools of clinical diarrhoeic and normal nonhuman primates in Kenya. Vet. Parasitol. 72, 141-147.

Nakauchi, K., 1999. The prevalence of Balantidium coli infection in fifty-six mammalian species. J. Vet. Med. Sci. 61, 63-65.

Nizeyi, J.B., Cranfield, M.R., Graczyk, T.K., 2002. Cattle near the Bwindi Impenetrable National Park, Uganda, as a reservoir of Cryptosporidium parvum and Giardia duodenalis for local community and free-ranging gorillas. Parasitol. Res. 88, 380-385.

O'Donoghue, P.J., 1995. Cryptosporidium and cryptosporidiosis in man and animal. Int. J. Parasitol. 25, 139-195.

Pang, V.F., Chang, C.C., Chang, W.F., 1993. Concurrent gastric and hepatic amebiasis in a dusky leaf monkey (Presbytis obscurus). J. Zoo Wildl. Med. 24, 204-207.

Peisert, W., Taborski, A., Pawlowski, Z., Karlewiczowa, R., Zdun, M., 1983. Giardia infection in animal Poznań Zoo. Vet. Parasitol. 13, 183-186.

Stauffer, W., Ravdin, I.J., 2003. Entamoeba histolytica: an update. Curr. Opin. Infect. Dis. 16, 479-485.

Tanyuksel, M., Petri, W.A., 2003. Laboratory diagnosis of amebiasis. Clin. Microbiol. Rev. 16, 713-729.

Teare, J.A., Loomis, M.R., 1982. Epizootic of balantidiasis in lowland gorillas. J. Am. Vet. Med. Assoc. 181, 1345-1347.

Thienpont, D., Rochettte, F., Van Parijs, O.F., 1986. Diagnosing Helminthiasis by Coprological Examination, 2nd ed. Janssen Research Foundation, Beerse, pp. 35-36.

Thompson, R.C.A., 2000. Giardiasis as a re-emerging infectious disease and its zoonotic potential. Int. J. Parasitol. 30, 1259-1267.

Thompson, R.C.A., Monis, P.T., 2004. Variation in Giardia: implications for taxonomy and epidemiology. Adv. Parasitol. 58, 69-137.

Thompson, R.C.A., Hopkins, R.M., Homan, W.L., 2000. Nomenclature and genetic groupings of Giardia infecting mammals. Parasitol. Today 16, 210-213.

Verweij, J.J., Polderman, A.M., Clark, C.G., 2001. Genetic variation among human isolates of uninucleated cyst-producing Entamoeba species. J. Clin. Microbiol. 39, 1644-1646.

Verweij, J.J., Vermeer, J., Brienen, E.A.T., Blotkamp, C., Laeijendecker, D., van Lieshout, L., Polderman, A.M., 2003a. Entamoeba histolytica infections in captive primates. Parasitol. Res. 90, 100-103.

Verweij, J.J., Laeijendecker, D., Brienen, E.A.T., Van Lieshout, L., Van Polderman, A.M., 2003b. Detection and identification of Entamoeba species by reverse line hybridisation in stool samples. J. Clin. Microbiol 41, 5141-5145.

Vitazkova, S.K., Wade, S.E., 2006. Parasites of free ranging black howler monkeys, Alouatta pigra, from Belize and Mexico. Am. J. Primatol. 68, 1089-1097. 